\author{
Military Technical College \\ Kobry El-Kobbah, \\ Cairo, Egypt
}

\author{
$14^{\text {th }}$ International Conference on \\ Applied Mechanics and \\ Mechanical Engineering.
}

\title{
The Effect of Indenter Geometrical Errors on the Accuracy And Uncertainty of Brinell Hardness
}

By
R. Hegazy *
M.Ibrahim **
A. Abuelezz ***
M. El-Sherbiny

\begin{abstract}
:
This paper reports work carried out to determine the influence of the ball indenter geometrical errors on the accuracy of Brinell hardness measurements. Indenters with nominal diameters of $1,2.5$, and $5 \mathrm{~mm}$ diameter are tested. Fifteen balls are considered for each nominal diameter. The roundness error of each ball is measured. The diameters of the balls were measured by profile projector and the roundness error was measured by CMM machine. The influence of the ball geometry on the accuracy of hardness is investigated. Six calibrated reference hardness-test blocks are used to perform Brinell hardness test using the 45 selected balls. The results show that the roundness error considerably affects the accuracy of the hardness measurement.
\end{abstract}

\section{Keywords:}

Brinell hardness, Brinell Indenter geometry , 
* Research Assistant, National Institute of Standards, Egypt

** Assoc. Prof, National Institute of Standards, Egypt

*** Professor, National Institute of Standards, Egypt

*** Professor, Faculty of Engineering, Cairo University, Egypt

\section{Introduction:}

Hardness is a measure of a material's resistance to local deformation caused by an indentation from a hard body. The most common indentation hardness tests in industry are Brinell, Vickers, and Rockwell.

\section{1-1 Brinell hardness test}

The Brinell hardness test method consists of indenting the test material with a hardened steel or carbide ball subjected to a load. The diameter of the indentation left in the test material is measured with a low powered microscope. The Brinell hardness number is calculated by dividing the load applied by the surface area of the indentation as shown in equation (1).

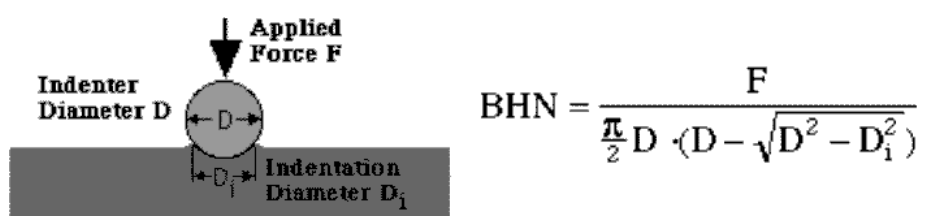

The diameter of the impression is the average of two readings at right angles. A well structured Brinell hardness number reveals the test conditions, and looks like this, "75 HB $1 / 30 / 30$ which means that a Brinell hardness of 75 was obtained using a $1 \mathrm{~mm}$ diameter hardened steel ball with a 30 kilogram load applied for a period of 30 seconds respectively. On tests of extremely hard metals, a tungsten carbide ball is substituted for the steel ball. Compared to the other hardness test methods, the Brinell ball makes the deepest and widest indentation, so the test averages the hardness over a wider amount of material, which more accurately accounts for multiple grain structures and any irregularities in the uniformity of the material [1].

The "true value" of hardness is achieved by the "ideal operator", using the "ideal standards hardness calibration machine" with the "ideal indenter" and working to the standards without any error [2]. In practice, it is impossible to realize the true value of the hardness scale, because the hardness machine and indenter cannot be manufactured and calibrated without tolerances. However, by controlling and reducing such tolerances of the reference standards, both random and systematic errors and their uncertainty contribution to the hardness scales can be minimized.

It has been recognized that different indenters, of nominally similar geometry, can lead to large variations in measured hardness values [3]. It has been identified that Brinell indenter morphology will contribute to the uncertainty in the hardness measurement. Therefore, it would be advisable to investigate these effects. The work described in this paper aims to quantify the effect of different indenter geometries on measured Brinell hardness. 


\section{2-Experimental set up}

The diameters of fifteen balls are measured by the profile projector $\mathrm{P} \mathrm{J}-250$ shown in Fig (1). It is Mitutoyo bench top single lens mount, model PJ250, with 20x Objective, 9" diameter rotating projection screen, and, 2-Axis digital micrometer stage. It utilizes surface reflection attachment and graduated chart ring.

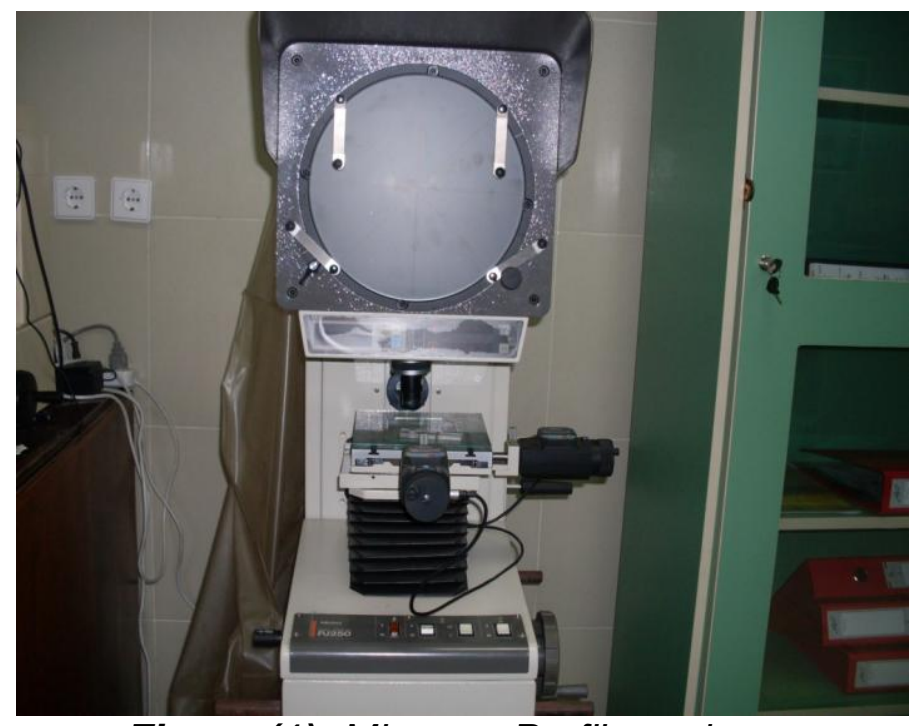

Figure (1): Mitutoyo Profile projector

The roundness of ten indenters from each nominal size are measured by PRISMO Carl Zeiss Coordinate Measuring machine (CMM), verified according to ISO 10360 which is shown in Fig (2).

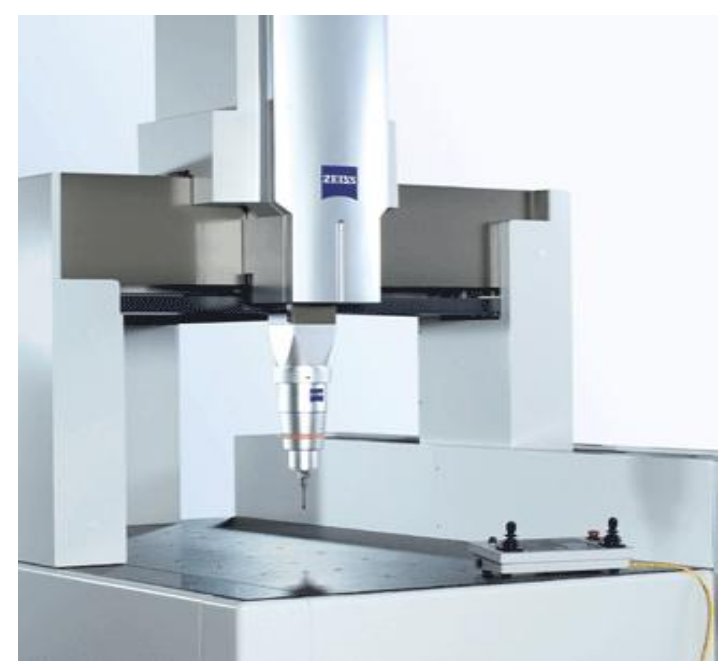

Fig (2): PRISMO CMM

The roundness deviation of measured circumferential circles is based on the Egyptian standard ES-NO.:779[4] with the following strategy:

No of points over each circumference circle:

Stylus tip radius:

Probing force:

100 to 120 point

$0.75 \mathrm{~mm}$

$100 \mathrm{mN}$ 
Scanning speed:

Reference circle:

$1 \mathrm{~mm} / \mathrm{sec}$

Least square circle (LSC)

The measurement of the roundness deviation is taken around five circles at five different locations randomly distributed over the surface of each ball.

\section{3-Results}

\section{3-1 Measuring the diameter of the balls:}

Fifteen balls from each nominal diameter were measured. Five measurements were taken for each ball randomly from different positions as shown in tables 1-3

(Table I): diameters of the balls with $5 \mathrm{~mm}$ nominal diameter

\begin{tabular}{|r|r|r|r|r|r|r|}
\hline Ball No. & $\begin{array}{l}\text { Measure(1) } \\
\mathbf{m m}\end{array}$ & $\begin{array}{l}\text { Measure(2) } \\
\mathbf{m m}\end{array}$ & $\begin{array}{l}\text { Measure(3) } \\
\mathbf{m m}\end{array}$ & $\begin{array}{l}\text { Measure(4) } \\
\mathbf{m m}\end{array}$ & $\begin{array}{l}\text { Measure(5) } \\
\mathbf{m m}\end{array}$ & \multicolumn{2}{l|}{$\begin{array}{l}\text { Average } \\
\mathbf{m m}\end{array}$} \\
\hline 1 & 5.012 & 5.015 & 5.004 & 5.016 & 5.014 & 5.0122 \\
\hline 2 & 5.006 & 5.007 & 5.001 & 4.995 & 4.991 & 5.000 \\
\hline 3 & 4.99 & 5.009 & 5.007 & 5.005 & 5.009 & 5.004 \\
\hline 4 & 5.006 & 5.005 & 5.006 & 5.004 & 5.005 & 5.0052 \\
\hline 5 & 5.001 & 5.002 & 4.995 & 5.001 & 5.001 & 5.000 \\
\hline 6 & 5.001 & 4.997 & 4.998 & 4.996 & 4.994 & 4.9972 \\
\hline 7 & 5.002 & 5.001 & 4.995 & 4.997 & 4.899 & 4.9788 \\
\hline 8 & 4.998 & 4.998 & 4.997 & 4.995 & 5 & 4.9976 \\
\hline 9 & 4.987 & 4.991 & 4.985 & 4.991 & 5.001 & 4.991 \\
\hline 10 & 4.99 & 5.001 & 5.002 & 4.996 & 4.986 & 4.995 \\
\hline 11 & 5.009 & 5.012 & 5.008 & 5.007 & 5.009 & 5.009 \\
\hline 12 & 5.014 & 5.007 & 5.004 & 5.016 & 5.015 & 5.011 \\
\hline 13 & 5.005 & 5.014 & 5.013 & 5.014 & 5.012 & 5.012 \\
\hline 14 & 5.005 & 5.009 & 5.007 & 5.006 & 5.008 & 5.007 \\
\hline 15 & 4.998 & 5.005 & 5.007 & 5.011 & 5.004 & 5.005 \\
\hline
\end{tabular}

(Table 2): Diameters of the balls with $2.5 \mathrm{~mm}$ nominal diameter

\begin{tabular}{|r|r|r|r|r|r|r|}
\hline Ball No. & $\begin{array}{l}\text { Measure(1) } \\
\mathrm{mm}\end{array}$ & $\begin{array}{l}\text { Measure(2) } \\
\mathrm{mm}\end{array}$ & $\begin{array}{l}\text { Measure(3) } \\
\mathrm{mm}\end{array}$ & $\begin{array}{l}\text { Measure(4) } \\
\mathrm{mm}\end{array}$ & $\begin{array}{l}\text { Measure(5) } \\
\mathrm{mm}\end{array}$ & $\begin{array}{l}\text { Average } \\
\mathrm{mm}\end{array}$ \\
\hline 1 & 2.504 & 2.505 & 2.501 & 2.501 & 2.501 & 2.5024 \\
\hline 2 & 2.504 & 2.504 & 2.502 & 2.505 & 2.504 & 2.5038 \\
\hline 3 & 2.504 & 2.5 & 2.5 & 2.502 & 2.499 & 2.501 \\
\hline 4 & 2.499 & 2.495 & 2.503 & 2.502 & 2.504 & 2.5006 \\
\hline 5 & 2.503 & 2.505 & 2.503 & 2.502 & 2.504 & 2.5034 \\
\hline 6 & 2.496 & 2.502 & 2.499 & 2.494 & 2.504 & 2.499 \\
\hline 7 & 2.494 & 2.491 & 2.501 & 2.502 & 2.492 & 2.496 \\
\hline 8 & 2.499 & 2.498 & 2.503 & 2.502 & 2.498 & 2.5 \\
\hline 9 & 2.503 & 2.495 & 2.5 & 2.498 & 2.499 & 2.499 \\
\hline 10 & 2.495 & 2.497 & 2.502 & 2.497 & 2.5 & 2.498 \\
\hline
\end{tabular}




\begin{tabular}{|r|r|r|r|r|r|r|}
\cline { 2 - 7 } 11 & 2.504 & 2.502 & 2.503 & 2.505 & 2.506 & 2.504 \\
\hline 12 & 2.509 & 2.507 & 2.508 & 2.51 & 2.512 & 2.509 \\
\hline 13 & 2.501 & 2.501 & 2.506 & 2.507 & 2.508 & 2.505 \\
\hline 14 & 2.502 & 2.503 & 2.499 & 2.498 & 2.498 & 2.500 \\
\hline 15 & 2.508 & 2.509 & 2.509 & 2.515 & 2.514 & 2.511 \\
\hline
\end{tabular}

(Table 3): Diameters of the balls with $1 \mathrm{~mm}$ nominal diameter

\begin{tabular}{|c|c|c|c|c|c|c|}
\hline & $\begin{array}{l}\text { Measure(1) } \\
\mathrm{mm}\end{array}$ & $\begin{array}{l}\text { Measure(2) } \\
\mathrm{mm}\end{array}$ & $\begin{array}{l}\text { Measure(3) } \\
\mathrm{mm}\end{array}$ & $\begin{array}{l}\text { Measure(4) } \\
\mathrm{mm}\end{array}$ & $\begin{array}{l}\text { Measure(5) } \\
\mathrm{mm}\end{array}$ & $\begin{array}{l}\text { Average } \\
\mathrm{mm}\end{array}$ \\
\hline 1 & 1.005 & 1.002 & 1.003 & 1.004 & 1.002 & 1.0032 \\
\hline 2 & 1.012 & 1.004 & 1.002 & 0.998 & 1.001 & 1.0034 \\
\hline 3 & 1.001 & 1.001 & 1.002 & 1.008 & 1.019 & 1.0062 \\
\hline 4 & 1.008 & 1.006 & 0.997 & 0.999 & 0.998 & 1.0016 \\
\hline 5 & 1.006 & 1.004 & 1.004 & 1.004 & 1.007 & 1.005 \\
\hline 6 & 0.997 & 0.997 & 1.001 & 0.994 & 1.001 & 0.998 \\
\hline 7 & 0.992 & 0.993 & 1.004 & 0.999 & 0.997 & 0.997 \\
\hline 8 & 0.985 & 0.989 & 0.995 & 0.998 & 0.988 & 0.991 \\
\hline 9 & 1.003 & 1.004 & 1.001 & 0.998 & 0.999 & 1.001 \\
\hline 10 & 0.985 & 0.986 & 0.989 & 0.99 & 0.99 & 0.988 \\
\hline 11 & 1.008 & 1.009 & 1.011 & 1.014 & 1.013 & 1.011 \\
\hline 12 & 1.006 & 1.005 & 1.011 & 1.012 & 1.011 & 1.009 \\
\hline 13 & 1.009 & 1.008 & 1.015 & 1.016 & 1.012 & 1.012 \\
\hline 14 & 1.016 & 1.017 & 1.018 & 1.018 & 1.016 & 1.017 \\
\hline 15 & 1.009 & 1.008 & 1.004 & 1.007 & 1.007 & 1.007 \\
\hline
\end{tabular}

As shown in tables 1-3, balls of $5 \mathrm{~mm}$ nominal diameter vary from $4.9788 \mathrm{~mm}$ to $5.0122 \mathrm{~mm}$. The variations of the diameters yield a range of $0.0334 \mathrm{~mm}$; which is $0.6 \%$ of the nominal diameter. For balls 2.5 the range of the diameter variation is $0.015 \mathrm{~mm}$ which equal to $0.6 \%$ from the nominal diameter, while for the balls with nominal diameter $1 \mathrm{~mm}$ the range is $0.029 \mathrm{~mm}$, rising up to $2.9 \%$ from the nominal diameter, It also indicate that the percentage variations is much higher at smaller indenter sizes.

\section{3-2 Roundness error}

Ten balls from each nominal diameter $5,2.5$, and $1 \mathrm{~mm}$ were used to measure the roundness error by CMM machine, as shown from tables 4-6.

(Table 4): the roundness error of the $5 \mathrm{~mm}$ balls

\begin{tabular}{|c|c|c|}
\hline No. & Diameter $\mathrm{mm}$ & $\begin{array}{c}\text { Roundness error } \\
\mu \mathrm{m}\end{array}$ \\
\hline 1 & 5.0122 & 2.5 \\
\hline 2 & 5 & 2.4 \\
\hline 3 & 5.004 & 2.2 \\
\hline 4 & 5.0052 & 2.2 \\
\hline 5 & 5 & 2.4 \\
\hline 6 & 4.9972 & 3.2 \\
\hline
\end{tabular}




\begin{tabular}{|c|c|c|}
\cline { 2 - 3 } 7 & 4.9788 & 2.4 \\
\hline 8 & 4.9976 & 2.2 \\
\hline 9 & 4.991 & 1.9 \\
\hline 10 & 4.995 & 2.3 \\
\hline
\end{tabular}

(Table 5): The roundness error of the $2.5 \mathrm{~mm}$ balls

\begin{tabular}{|r|c|l|}
\hline Ball No. & Diameter $\mathbf{m m}$ & $\begin{array}{l}\text { Roundness error } \\
\boldsymbol{\mu m}\end{array}$ \\
\hline 1 & 2.5024 & 2.6 \\
\hline 2 & 2.5038 & 3.8 \\
\hline 3 & 2.501 & 3.3 \\
\hline 4 & 2.5006 & 4.5 \\
\hline 5 & 2.5034 & 5.4 \\
\hline 6 & 2.499 & 7.3 \\
\hline 7 & 2.496 & 5.2 \\
\hline 8 & 2.5 & 2.7 \\
\hline 9 & 2.499 & 7.7 \\
\hline 10 & 2.4982 & 7.2 \\
\hline
\end{tabular}

(Table 6): The roundness error of the $1 \mathrm{~mm}$ balls

\begin{tabular}{|c|c|c|}
\hline Ball No. & Diameter $\mathbf{~ m m}$ & $\begin{array}{c}\text { Roundness error } \\
\boldsymbol{m m}\end{array}$ \\
\hline 1 & 1.0026 & 5.1 \\
\hline 2 & 1.0034 & 5.4 \\
\hline 3 & 1.0062 & 6.1 \\
\hline 4 & 1.0016 & 6.5 \\
\hline 5 & 1.005 & 5.2 \\
\hline 6 & 0.998 & 7.2 \\
\hline 7 & 0.997 & 7.2 \\
\hline 8 & 1 & 7.8 \\
\hline 9 & 1.001 & 8.2 \\
\hline 10 & 0.988 & 7.1 \\
\hline
\end{tabular}

It is shown that the maximum roundness error of the balls with nominal diameters of $5,2.5$, and $1 \mathrm{~mm}$ are $3.2,7.7,8.2 \mu \mathrm{m}$ respectively.

\section{3-3 The effect of the ball diameter on the hardness value:}

Each ball from all nominal diameters was used to perform hardness test on two different calibrated reference blocks with two different hardness values 219 and $450 \mathrm{HB}$. Forty-five balls were used to perform hardness test. Each test was carried out with five indentations. The average of five indentations is obtained. The tests were performed according to the 
ISO/CD 5606-1[5] .Tables 7-12, and figures 3-8 show the effect of ball diameter in Brinell hardness values.

The confidence level of $95 \%$ is taken for the analysis of the hardness values as limits of \pm 2Se where (Se) is the standard error of estimate which is calculated from the following equation (2) [6]:

$S e=\sum_{n}^{i=1} \sqrt{\frac{(y i-y c)^{2}}{n-2}}$

$\mathrm{Se}=$

Where

$\mathrm{yi}$ : is the experimental hardness value

yc: The calculated hardness value from the equation of the trend line $\mathrm{n}$ : the No. of readings $=15$

(Table 7): Effect of ball diameter on hardness No, 219 \pm 2 HBW

\begin{tabular}{|c|c|c|c|c|c|c|c|}
\hline $\begin{array}{c}\text { Ball } \\
\text { diameter } \\
\text { mm }\end{array}$ & $\begin{array}{c}\text { Range } \\
\text { mm }\end{array}$ & HB1 & HB2 & HB3 & HB4 & HB5 & $\begin{array}{c}\text { Average } \\
\text { HB }\end{array}$ \\
\hline 5.0122 & 0.012 & 218 & 217 & 217 & 218 & 218 & 217.6 \\
\hline 5 & 0.016 & 222 & 220 & 220 & 219 & 221 & 220.4 \\
\hline 5.004 & 0.019 & 220 & 218 & 220 & 219 & 221 & 219.6 \\
\hline 5.0052 & 0.002 & 219 & 220 & 218 & 219 & 219 & 219 \\
\hline 5 & 0.007 & 220 & 220 & 220 & 221 & 222 & 220.6 \\
\hline 4.9972 & 0.007 & 221 & 221 & 220 & 220 & 219 & 220.2 \\
\hline 4.9788 & 0.103 & 225 & 224 & 225 & 225 & 224 & 224.6 \\
\hline 4.9976 & 0.005 & 222 & 221 & 222 & 221 & 221 & 221.4 \\
\hline 4.991 & 0.016 & 221 & 222 & 223 & 223 & 223 & 222.4 \\
\hline 4.995 & 0.016 & 222 & 221 & 221 & 221 & 220 & 221 \\
\hline 5.009 & 0.005 & 219 & 216 & 219 & 218 & 218 & 218 \\
\hline 5.011 & 0.012 & 218 & 217 & 219 & 219 & 218 & 218.2 \\
\hline 5.012 & 0.009 & 219 & 218 & 217 & 219 & 217 & 218 \\
\hline 5.007 & 0.004 & 219 & 219 & 218 & 220 & 219 & 219 \\
\hline 5.005 & 0.013 & 218 & 220 & 218 & 219 & 218 & 218.6 \\
\hline
\end{tabular}




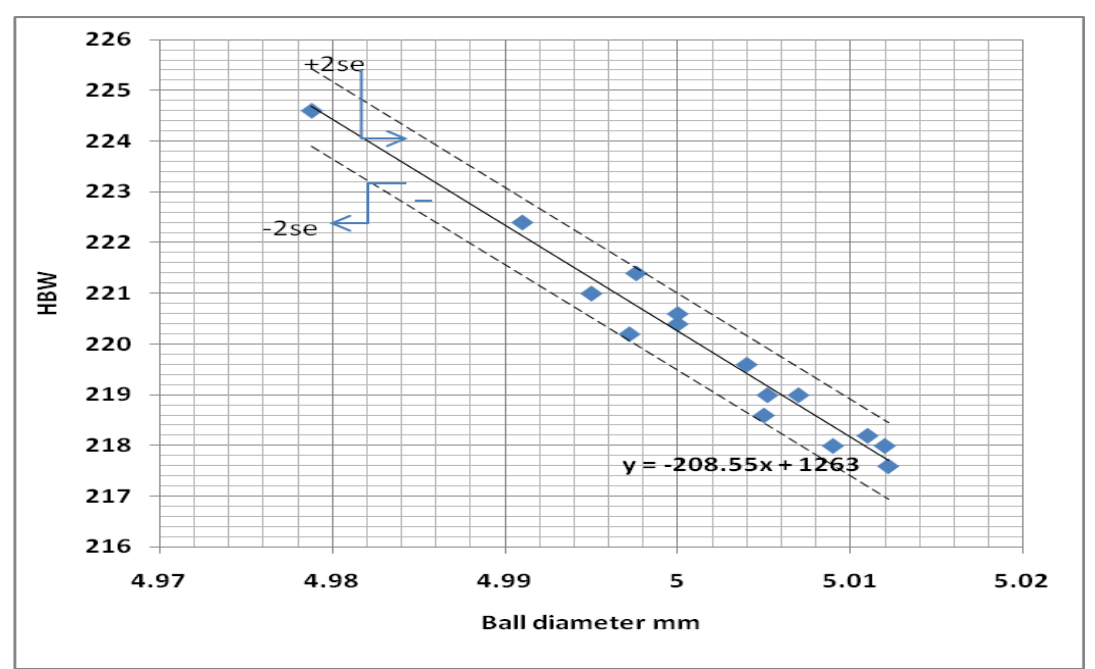

(Fig 3): Relation between ball diameter of the indenter and hardness No (Ball $5 \mathrm{~mm} 219 \mathrm{HBW}$ )

(Table 8): Effect of ball diameter on hardness No, Ball $5 \mathrm{~mm}, 449 \pm 2 \mathrm{HBW}$

\begin{tabular}{|c|c|c|c|c|c|c|c|}
\hline $\begin{array}{c}\text { Ball } \\
\text { diameter } \\
\mathrm{mm}\end{array}$ & $\begin{array}{c}\text { Range } \\
\mathrm{mm}\end{array}$ & HB1 & HB2 & HB3 & HB4 & HB5 & $\begin{array}{c}\text { Average } \\
\text { HB }\end{array}$ \\
\hline 5.0122 & 0.012 & 448 & 447 & 446 & 447 & 447 & 447 \\
\hline 5 & 0.016 & 450 & 450 & 450 & 451 & 449 & 450 \\
\hline 5.004 & 0.019 & 448 & 450 & 448 & 449 & 449 & 448.8 \\
\hline 5.0052 & 0.002 & 448 & 449 & 448 & 449 & 449 & 448.6 \\
\hline 5 & 0.007 & 450 & 450 & 449 & 451 & 449 & 449.8 \\
\hline 4.9972 & 0.007 & 450 & 451 & 451 & 452 & 450 & 450.8 \\
\hline 4.9788 & 0.103 & 456 & 458 & 457 & 458 & 456 & 457 \\
\hline 4.9976 & 0.005 & 451 & 452 & 452 & 452 & 451 & 451.6 \\
\hline 4.991 & 0.016 & 452 & 452 & 453 & 453 & 452 & 452.4 \\
\hline 4.995 & 0.016 & 452 & 452 & 452 & 453 & 453 & 452.4 \\
\hline 5.009 & 0.005 & 448 & 447 & 447 & 447 & 448 & 447.4 \\
\hline 5.011 & 0.012 & 447 & 447 & 445 & 449 & 447 & 447 \\
\hline 5.012 & 0.009 & 448 & 446 & 446 & 447 & 447 & 446.8 \\
\hline 5.007 & 0.004 & 448 & 448 & 447 & 449 & 447 & 447.8 \\
\hline 5.005 & 0.013 & 448 & 450 & 448 & 449 & 449 & 448.8 \\
\hline
\end{tabular}




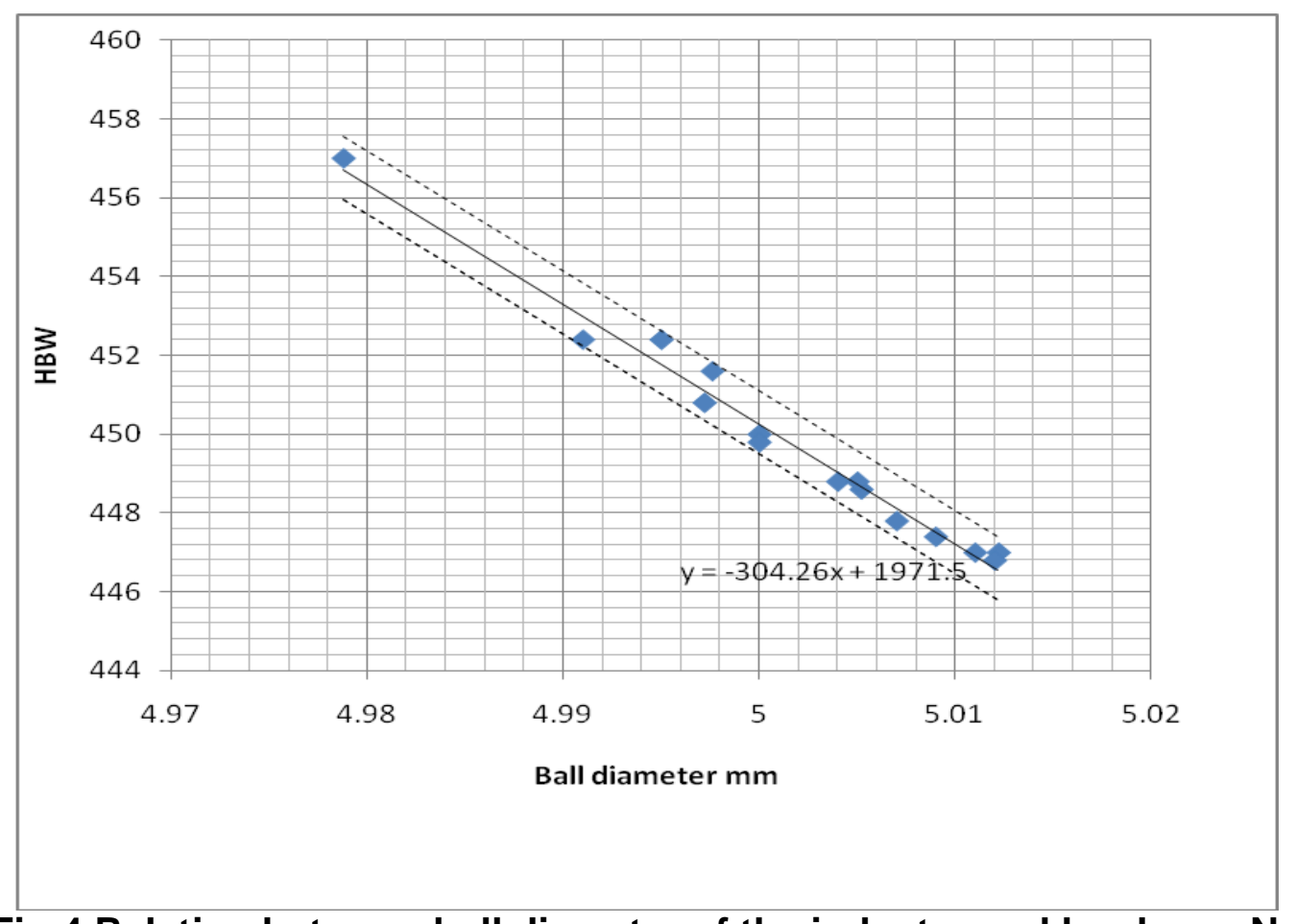

Fig 4 Relation between ball diameter of the indenter and hardness No (Ball 5mm 449HBW)

(Table 9): Effect of ball diameter on hardness No, Ball 2.5mm, 449 $\pm 1.5 \mathrm{HBW}$

\begin{tabular}{|c|c|c|c|c|c|c|c|}
\hline $\begin{array}{c}\text { Ball } \\
\text { diameter } \\
\mathrm{mm}\end{array}$ & $\begin{array}{c}\text { Range } \\
\mathrm{mm}\end{array}$ & HB1 & HB2 & HB3 & HB4 & HB5 & $\begin{array}{c}\text { Average } \\
\text { HB }\end{array}$ \\
\hline 2.50240 & 0.004 & 448 & 447 & 448 & 449 & 446 & 447.6 \\
\hline 2.50380 & 0.003 & 445 & 448 & 447 & 448 & 446 & 446.8 \\
\hline 2.50100 & 0.005 & 449 & 449 & 450 & 450 & 450 & 449.6 \\
\hline 2.50060 & 0.009 & 449 & 450 & 451 & 450 & 449 & 449.8 \\
\hline 2.50340 & 0.003 & 447 & 446 & 448 & 447 & 447 & 447 \\
\hline 2.49900 & 0.01 & 455 & 455 & 454 & 454 & 454 & 454.4 \\
\hline 2.49600 & 0.011 & 457 & 458 & 459 & 455 & 456 & 457 \\
\hline 2.50000 & 0.005 & 450 & 453 & 451 & 454 & 452 & 451.2 \\
\hline 2.49900 & 0.008 & 450 & 452 & 453 & 454 & 454 & 452.6 \\
\hline 2.49820 & 0.007 & 456 & 458 & 455 & 454 & 455 & 455.6 \\
\hline 2.50400 & 0.004 & 448 & 448 & 449 & 447 & 447 & 447.8 \\
\hline 2.50920 & 0.005 & 445 & 446 & 446 & 445 & 444 & 445.2 \\
\hline 2.50460 & 0.007 & 447 & 447 & 446 & 447 & 446 & 446.6 \\
\hline 2.50000 & 0.005 & 450 & 450 & 451 & 451 & 451 & 450.6 \\
\hline 2.51100 & 0.007 & 445 & 443 & 445 & 444 & 443 & 444 \\
\hline
\end{tabular}




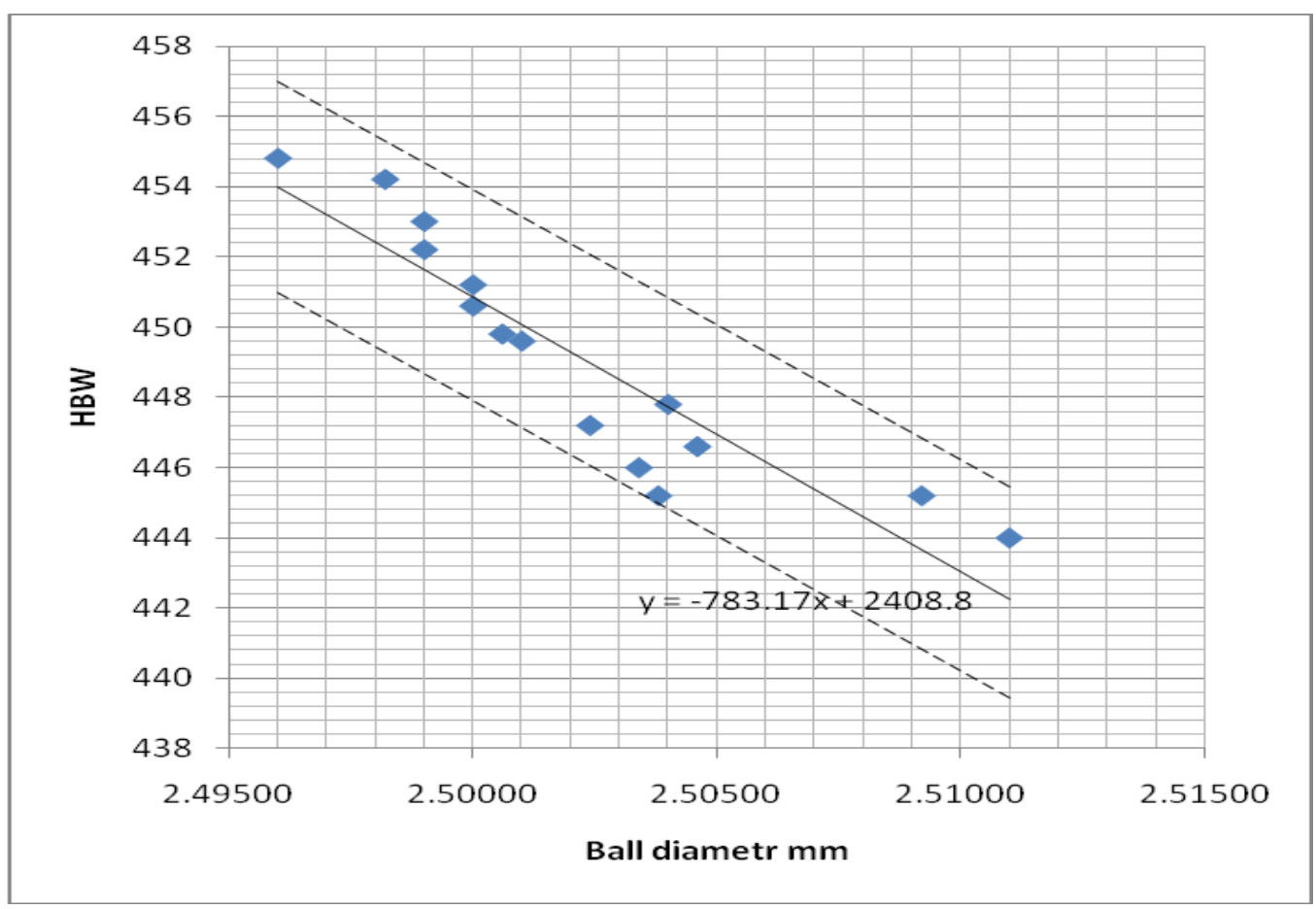

(Fig 5): Relation between ball diameter of the indenter and hardness No (Ball 2.5mm 449HBW)

(Table 10): Effect of ball diameter on hardness No, Ball 2.5mm, 218.8 $\pm 1 \mathrm{HBW}$

\begin{tabular}{|c|c|c|c|c|c|c|c|}
\hline $\begin{array}{c}\text { Ball } \\
\text { diameter } \\
\text { mm }\end{array}$ & $\begin{array}{c}\text { Range } \\
\mathrm{mm}\end{array}$ & HB1 & HB2 & HB3 & HB4 & HB5 & $\begin{array}{c}\text { Average } \\
\text { HB }\end{array}$ \\
\hline 2.50240 & 0.004 & 218 & 218 & 217 & 217 & 219 & 217.8 \\
\hline 2.50380 & 0.003 & 217 & 218 & 217 & 217 & 218 & 217.4 \\
\hline 2.50100 & 0.005 & 218 & 218 & 219 & 219 & 218 & 218.4 \\
\hline 2.50060 & 0.009 & 219 & 219 & 218 & 219 & 219 & 218.8 \\
\hline 2.50340 & 0.003 & 217 & 217 & 217 & 218 & 217 & 217.2 \\
\hline 2.49900 & 0.01 & 222 & 219 & 220 & 222 & 222 & 221 \\
\hline 2.49600 & 0.011 & 222 & 220 & 222 & 220 & 221 & 221 \\
\hline 2.50000 & 0.005 & 218 & 220 & 220 & 218 & 219 & 219 \\
\hline 2.49900 & 0.008 & 223 & 223 & 223 & 220 & 222 & 222.2 \\
\hline 2.49820 & 0.007 & 221 & 221 & 222 & 221 & 222 & 221.4 \\
\hline 2.50400 & 0.004 & 218 & 217 & 218 & 217 & 217 & 217.4 \\
\hline 2.50920 & 0.005 & 217 & 217 & 215 & 216 & 215 & 216 \\
\hline 2.50460 & 0.007 & 216 & 216 & 216 & 218 & 217 & 216.6 \\
\hline 2.50000 & 0.005 & 218 & 218 & 219 & 218 & 219 & 218.4 \\
\hline 2.51100 & 0.007 & 216 & 215 & 214 & 214 & 215 & 214.8 \\
\hline
\end{tabular}




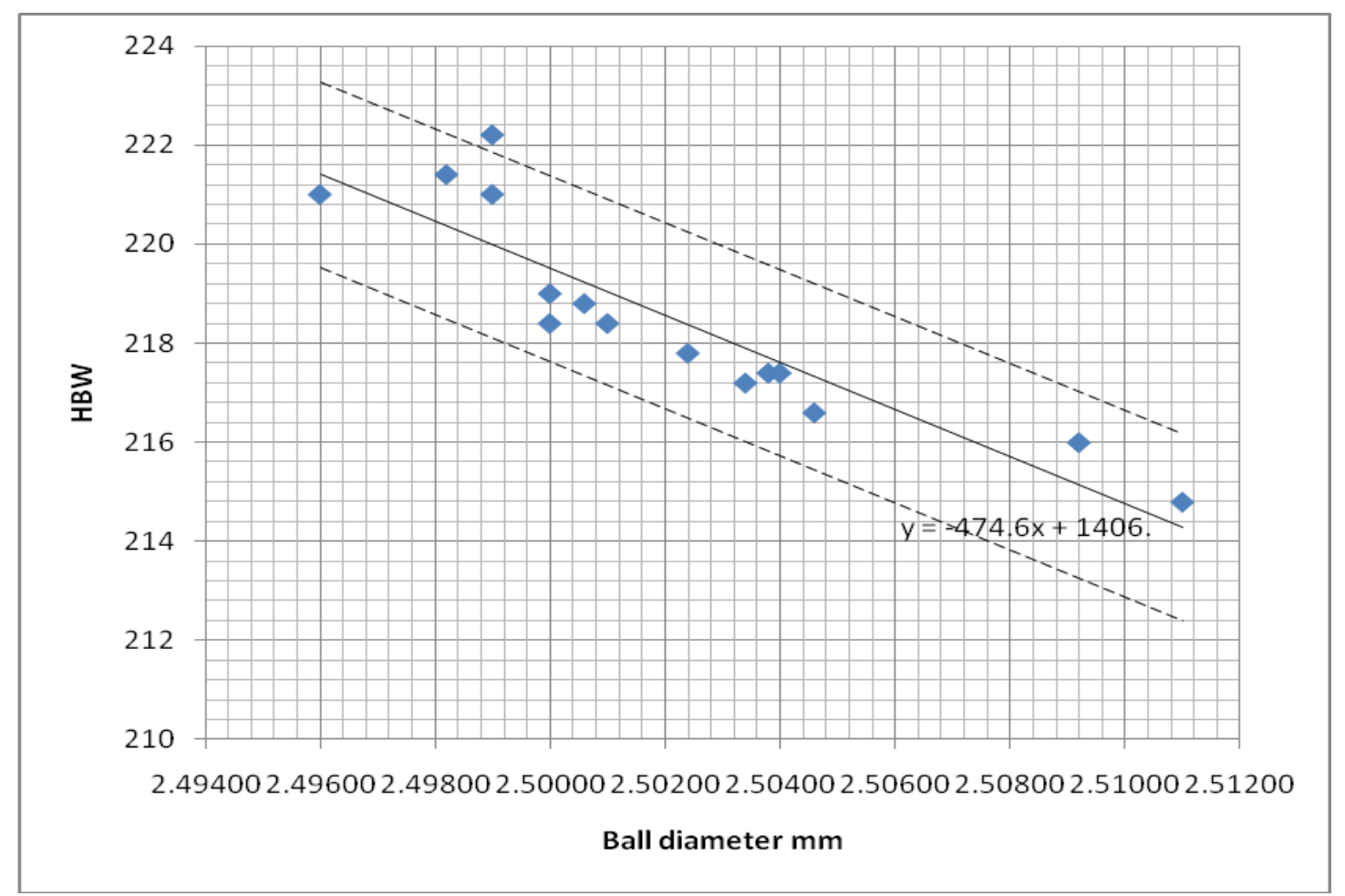

(Fig 6): Relation between ball diameter of the indenter and hardness No (Ball 2.5mm 218.8HBW)

(Table 11): Effect of ball diameter on hardness No, Ball 1mm, $450 \pm 1.5 \mathrm{HBW}$

\begin{tabular}{|c|c|c|c|c|c|c|c|}
\hline $\begin{array}{c}\text { Ball } \\
\text { diameter } \\
\mathrm{mm}\end{array}$ & $\begin{array}{c}\text { Range } \\
\mathrm{mm}\end{array}$ & HB1 & HB2 & HB3 & HB4 & HB5 & $\begin{array}{c}\text { Average } \\
\text { HB }\end{array}$ \\
\hline 1.0026 & 0.003 & 450 & 451 & 450 & 450 & 450 & 450.2 \\
\hline 1.0034 & 0.014 & 451 & 449 & 449 & 452 & 451 & 450.4 \\
\hline 1.0062 & 0.018 & 450 & 448 & 449 & 449 & 450 & 449.2 \\
\hline 1.0016 & 0.011 & 447 & 446 & 446 & 446 & 447 & 446.4 \\
\hline 1.005 & 0.003 & 449 & 449 & 448 & 448 & 448 & 448.4 \\
\hline 0.998 & 0.007 & 454 & 453 & 453 & 453 & 453 & 453.2 \\
\hline 0.997 & 0.012 & 454 & 454 & 453 & 454 & 455 & 454 \\
\hline 1 & 0.004 & 456 & 457 & 456 & 458 & 455 & 456.4 \\
\hline 1.001 & 0.006 & 455 & 454 & 454 & 453 & 454 & 454 \\
\hline 0.988 & 0.005 & 459 & 458 & 458 & 459 & 458 & 458.4 \\
\hline 1.011 & 0.006 & 448 & 447 & 447 & 446 & 447 & 447 \\
\hline 1.009 & 0.007 & 448 & 449 & 447 & 448 & 448 & 448 \\
\hline 1.012 & 0.008 & 447 & 448 & 448 & 448 & 447 & 447.6 \\
\hline 1.017 & 0.002 & 446 & 446 & 447 & 445 & 445 & 445.8 \\
\hline 1.007 & 0.005 & 449 & 449 & 450 & 448 & 449 & 449 \\
\hline
\end{tabular}




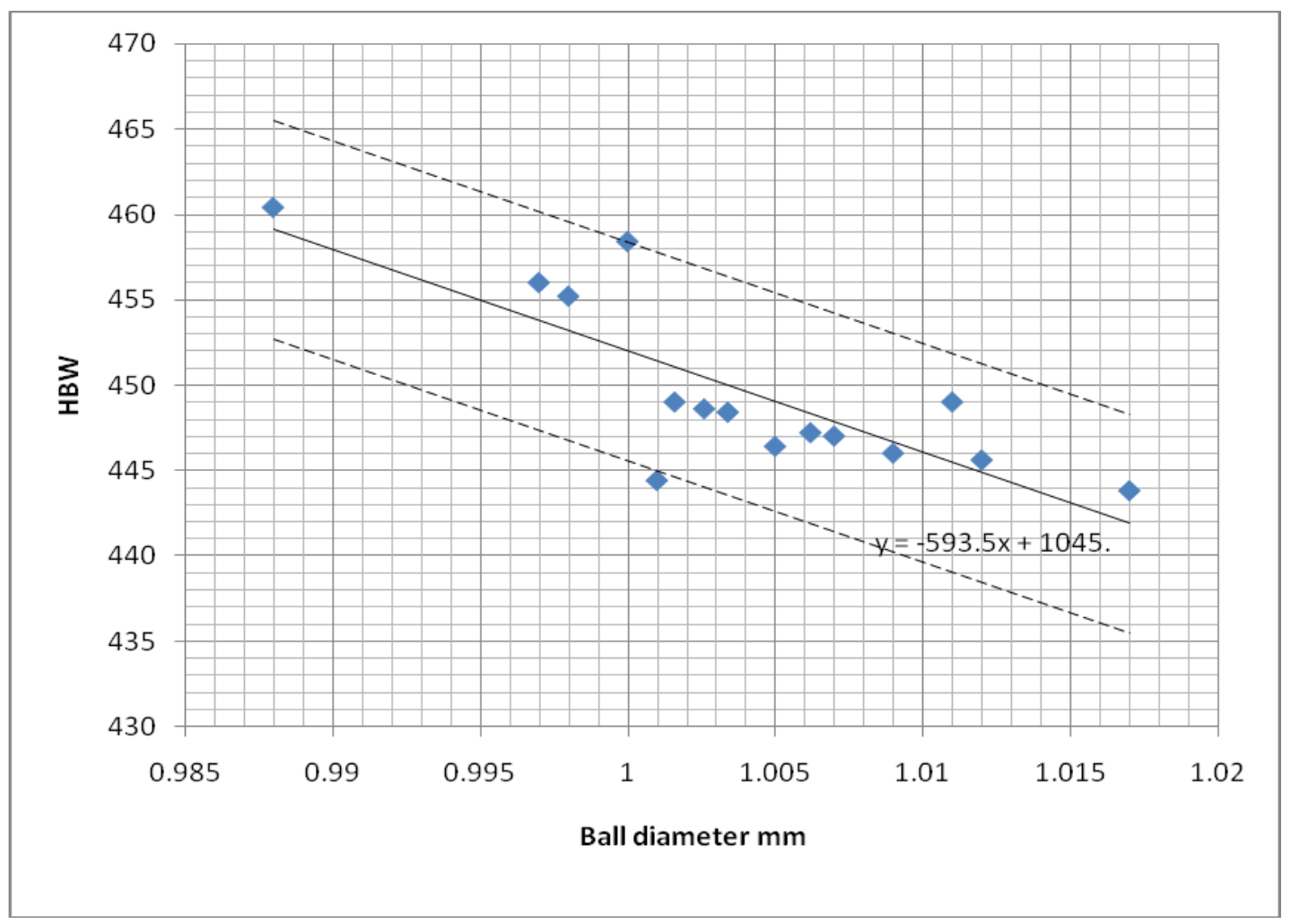

Fig 5 Relation between ball diameter of the indenter and hardness No, (Ball 1mm, $450 \mathrm{HBW}$ )

(Table 12): Effect of ball diameter on hardness No, Ball $1 \mathrm{~mm}, 215.2 \pm 2 \mathrm{HBW}$

\begin{tabular}{|c|c|c|c|c|c|c|c|}
\hline $\begin{array}{c}\text { Ball } \\
\text { diameter } \\
\text { mm }\end{array}$ & $\begin{array}{c}\text { Range } \\
\text { mm }\end{array}$ & HB1 & HB2 & HB3 & HB4 & HB5 & $\begin{array}{c}\text { Average } \\
\text { HB }\end{array}$ \\
\hline 1.0032 & 0.003 & 215 & 216 & 215 & 216 & 216 & 215.6 \\
\hline 1.0034 & 0.014 & 215 & 214 & 216 & 216 & 214 & 215 \\
\hline 1.0062 & 0.018 & 214 & 215 & 215 & 216 & 215 & 215 \\
\hline 1.0016 & 0.011 & 216 & 216 & 217 & 216 & 215 & 216 \\
\hline 1.005 & 0.003 & 216 & 215 & 215 & 215 & 214 & 215 \\
\hline 0.998 & 0.007 & 220 & 219 & 220 & 221 & 219 & 219.8 \\
\hline 0.997 & 0.012 & 218 & 219 & 218 & 220 & 219 & 218.8 \\
\hline 0.991 & 0.004 & 220 & 220 & 218 & 222 & 220 & 220 \\
\hline 1.001 & 0.006 & 219 & 217 & 217 & 217 & 218 & 217.6 \\
\hline 0.988 & 0.005 & 222 & 221 & 220 & 222 & 222 & 221.4 \\
\hline 1.011 & 0.006 & 210 & 211 & 210 & 212 & 212 & 211 \\
\hline 1.009 & 0.007 & 213 & 214 & 212 & 211 & 213 & 212.6 \\
\hline 1.012 & 0.008 & 211 & 212 & 210 & 212 & 213 & 211.6 \\
\hline 1.017 & 0.002 & 212 & 210 & 211 & 211 & 212 & 211.2 \\
\hline 1.007 & 0.005 & 213 & 214 & 215 & 214 & 215 & 214.2 \\
\hline
\end{tabular}




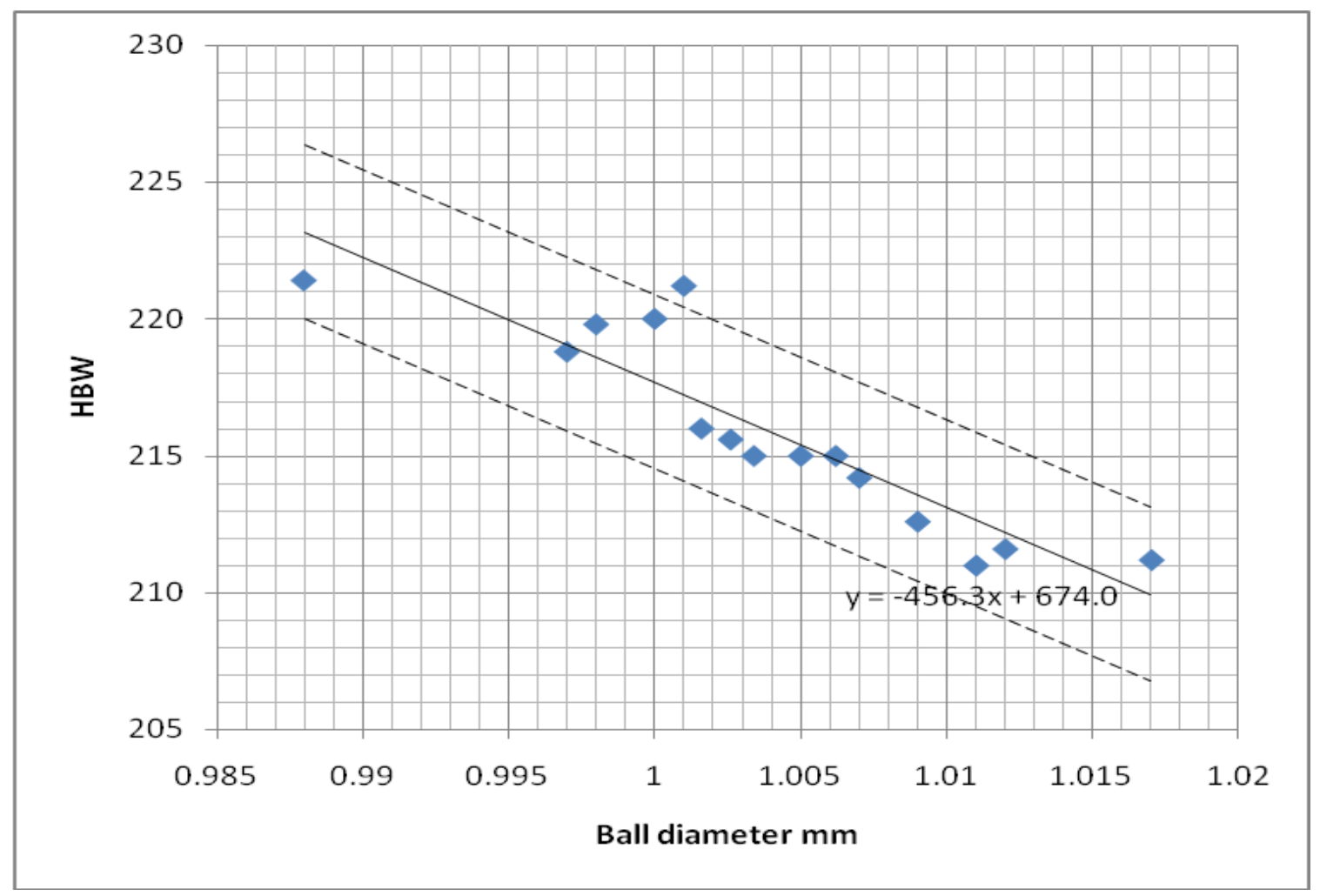

(Fig8): Relation between ball diameter of the indenter and hardness No, (Ball $1 \mathrm{~mm}, 215.2 \mathrm{HBW}$ )

It is shown that the hardness value increases by the decreasing of the ball indenter diameter. Figure (3) shows that the diameter variation of $0.033 \mathrm{~mm}$ for the $5 \mathrm{~mm}$ ball nominal diameter leads to corresponding Brinell hardness variation 7 HB i.e. about $3.19 \%$ for the hardness value of $219 \mathrm{HB}$. This means that every $1 \mu \mathrm{m}$ error in diameter of the ball gives a hardness error about $0.096 \%$; however, for balls of $2.5 \mathrm{~mm}$ nominal diameter, the hardness error is $3.4 \%$ for $0.015 \mathrm{~mm}$ variation in ball diameter in the same hardness value (218.8 HB). It follows that every $1 \mu \mathrm{m}$ error in diameter of the ball gives a hardness error about $0.23 \%$. Furthermore, for balls $1 \mathrm{~mm}$ nominal diameter the hardness error is $4.83 \%$ for $0.029 \mathrm{~mm}$ variation in nominal diameter, i.e. each $1 \mu \mathrm{m}$ error in diameter gives a hardness error of $0.17 \%$.

For the specimens with the hardness value of $449 \mathrm{HB}$, also the balls with 2.5 and $1 \mathrm{~mm}$ nominal diameter give hardness error higher than for $5 \mathrm{~mm}$. Balls $5 \mathrm{~mm}$ nominal diameter show for each $1 \mu \mathrm{m}$ variation in diameter $0.068 \%$ hardness error, while for balls 2.5 and $1 \mathrm{~mm}$ the variation in corresponding Brinell hardness are $0.19 \%, 0.12 \%$ respectively.

It is shown that the standard error of estimate $\mathrm{Se}$ is about $0.4 \mathrm{HB}$ for $5 \mathrm{~mm}$ nominal diameters ball for the two hardness values, and for balls 2.5 , and $1 \mathrm{~mm}$ nominal diameters are 1.5, and 3.2 HB respectively for $450 \mathrm{HB}$, and $0.9,1.6$ for $219 \mathrm{HB}$.

Estimated standard error as calculated from equation 2 gives an indication for the scattering of the results, which is mainly obtained from the roundness error.

Considering the balls No. 9 and 10 with diameters 2.499, $2.4998 \mathrm{~mm}$, they have the max roundness error of 7.7 and $7.2 \mu \mathrm{m}$ respectively, and showed pronounced scattering in the results. In addition, for balls $1 \mathrm{~mm}$ nominal diameter, the balls No. 8 and 9 with diameters 1 
and $1.001 \mathrm{~mm}$ have the maximum roundness error of 7.8 and $8 \mu \mathrm{m}$ respectively, and showed the same scattering in the results.

Considering the roundness error, it was shown from the results that the balls $2.5,1 \mathrm{~mm}$ have roundness errors higher than the balls $5 \mathrm{~mm}$ nominal diameter, which resulted in increase in the standard error of estimate $(\mathrm{Se})$ and the uncertainty values due to the scattering of the results. Figure 6-9 show that the balls with high roundness error values give higher scattering in results than the others.

\section{4- Conclusion}

The present study concerns with the effect of the ball indenter diameters and ball roundness error on the Brinell hardness value. It can be concluded that:

1 - The measured hardness value increased with decreasing the ball indenter diameter. This implies overestimating the hardness value by using smaller indenters.

2- The balls with nominal diameter of $5 \mathrm{~mm}, 2.5 \mathrm{~mm}$, and $1 \mathrm{~mm}$, had diameter variation of $0.0334,0.015$, and $0.029 \mathrm{~mm}$ respectively, which leads to corresponding Brinell hardness variation of $3.19,3.4$, and $4.83 \%$ respectively for the reference hardness value of 219 , and $2.2,2.4$, and $3.6 \%$ respectively for the 450 standard hardness value.

3- The balls with higher roundness error give high scattering in the results of the hardness test, which leads to a considerable effect on the uncertainty of the results.

4. The balls with nominal diameter of $2.499,2.4998$, and $1.001 \mathrm{~mm}$ have max roundness errors of $7.7,7.2,7.8,8 \mu \mathrm{m}$ respectively, and they have significant scattering in results,

\section{References}

[1] JOZEF PETRÍK, The Influence of the Ball on the Brinell Hardness Tester Calibration, Mapan-

Journal of metrology society of India, Vol.23, No. 4, 2008, pp. 197-205.

[2] Laurence Brice, Uncertainty in hardness measurements, NPL Report CMAM 87, April 2003.

[3] Laurence Brice, the Influence of indenter characteristics on hardness measurements, XVII IMEKO World Congress Metrology in the 3rd Millennium, June 22-27, 2003, Dubrovnik, Croatia.

[4] ES 779/2008 (The methods for determination of the roundness deviation).

[5] ISO/CD 5606-1 (Metallic materials-Brinell hardness test-test method).

[6] Edward Waltz, Understanding Confidence Intervals, lecture notes. 